\title{
Backprocessing paraffin wax blocks for subgross examination
}

\author{
J S Armstrong, J D Davies, B Hronkova
}

\begin{abstract}
A method called "backprocessing", for subgross examination of sections, ranging between $50 \mu \mathrm{m}$ and $1 \mathrm{~mm}$ in thickness using a dissecting microscope was developed. It requires either archival or current diagnostic breast tissue. In this study tissue is assumed to have been already embedded in paraffin wax for immediate diagnostic purposes. The advantages of backprocessing include the ability to select valuable or rare diagnostic tissue from archival histopathological material, and the preservation of histological structure should further examination at $5 \mu \mathrm{m}$ thickness be required at a later date.
\end{abstract}

(f Clin Pathol 1992;45:1116-1117)

In 1990 Babiak and Poppema described a method of dewaxing paraffin wax embedded tissue sections for DNA flow cytometric analysis of breast tumours. ${ }^{1}$ We have modified this method to perform "backprocessing" to allow subgross techniques to be applied to routinely processed breast tissue.

The process of subgross examination of tissue has fallen from favour. ${ }^{25}$ The technique relied on fresh or formalin fixed material, and due to the prolonged clearing required the sections took many days or even weeks to prepare. However, valuable information such as the extent of a lesion and its three-dimensional structure can be gleaned from such preparations. Indeed, the development of confocal microscopy may bring such neglected techniques back into vogue. Such instruments can scan depths of up to $2 \mathrm{~mm}$ of appropriately stained and cleared subgross preparations (Armstrong, personal observation).

The utility of the earlier techniques ${ }^{2-5}$ is further limited by the fact that the most interesting areas of a biopsy specimen have already been necessarily submitted for diagnostic paraffin wax block sectioning, and effective retrospective studies are otherwise made impossible by the limited storage of archival formalin fixed material. Many of the small lesions, ideal for such examination, are also incidental findings in histological sections.

"Backprocessing" obviates all these problems, opening large archives of tissue for subgross examination.

\section{Methods}

Formalin fixed tissue from mastectomy specimens was selected from both adipose and fibrous areas. This tissue had been routinely processed and embedded in paraffin wax blocks, prepared in a conventional manner. ${ }^{6}$ Sections were cut on a sledge microtome (Anglia Scientific, Cambridge) at depths of between $50 \mu \mathrm{m}$ and $1 \mathrm{~mm}$. The specimens were then dewaxed and rehydrated using a modified dewaxing protocol. ${ }^{1}$ All the tissue sections, regardless of thickness, were immersed in xylene for 24 hours. The xylene was replaced and then changed again after a further three hours. The tissue was rehydrated in $100 \%$ methyl alcohol, $95 \%$ wv methyl alcohol, and $70 \%$ and $50 \% \mathrm{wv}$ concentrations of methyl alcohol for three hours in each solution. Tissue was finally transferred to $10 \%$ wv formol-saline.

The tissue of five samples was then divided. Half of the specimen was reprocessed in a conventional manner as before, ${ }^{6}$ and a single $5 \mu \mathrm{m}$ haematoxylin and eosin stained section prepared from each block. The second half of the sample was processed as a subgross technique using a method modified from that of Manton et al. ${ }^{7}$

The dewaxed tissue was washed in running tap water for 15 minutes and then stained with Mayer's haematoxylin for 20 minutes. The tissue was washed in running water for 10 minutes to blue the sections and differentiated in $1 \%$ acid alcohol for 15 minutes. The tissue was washed again in running water for 15 minutes. The tissue was then dehydrated according to the method used by Manton et $a l .^{7}$ The sections were cleared by immersion in xylene for 24 hours and cedar wood oil for three days.

The thick sections were examined using both a conventional and dissecting microscope by placing the tissue on a Petri dish filled with cedar wood oil and covered with a glass cover slip. Sections were examined to assess the completeness of dewaxing and the quality of staining.

The conventional $5 \mu \mathrm{m}$ sections were examined to assess the damage to the cytological detail by the dewaxing procedure.

After this initial pilot study, sections were cut at similar depths from routine paraffin wax blocks of archival cases to facilitate subgross examination of small lesions. Sections were placed in tissue processing cassettes $(\mathrm{BDH}$, Eastleigh) and the dewaxing and subsequent subgross staining were performed in these cassettes as a batch procedure. 


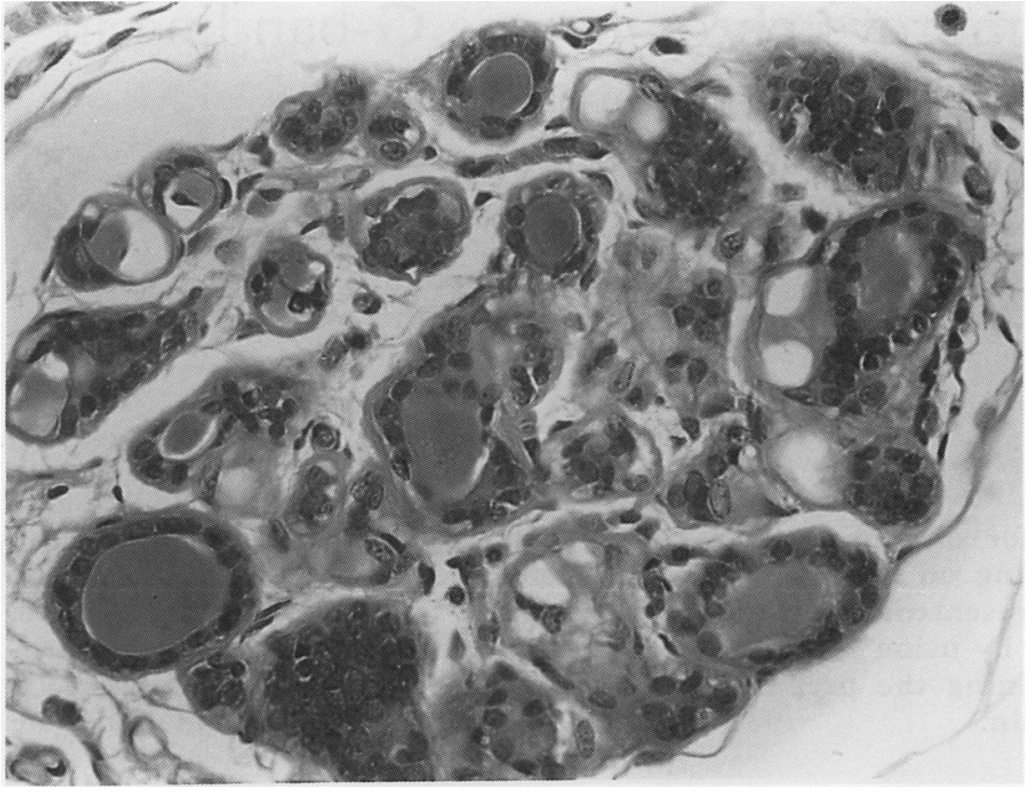

Figure $15 \mu \mathrm{m}$ haematoxylin and eosin stained section from a reprocessed block, illustrating excellent preservation of nuclear detail.

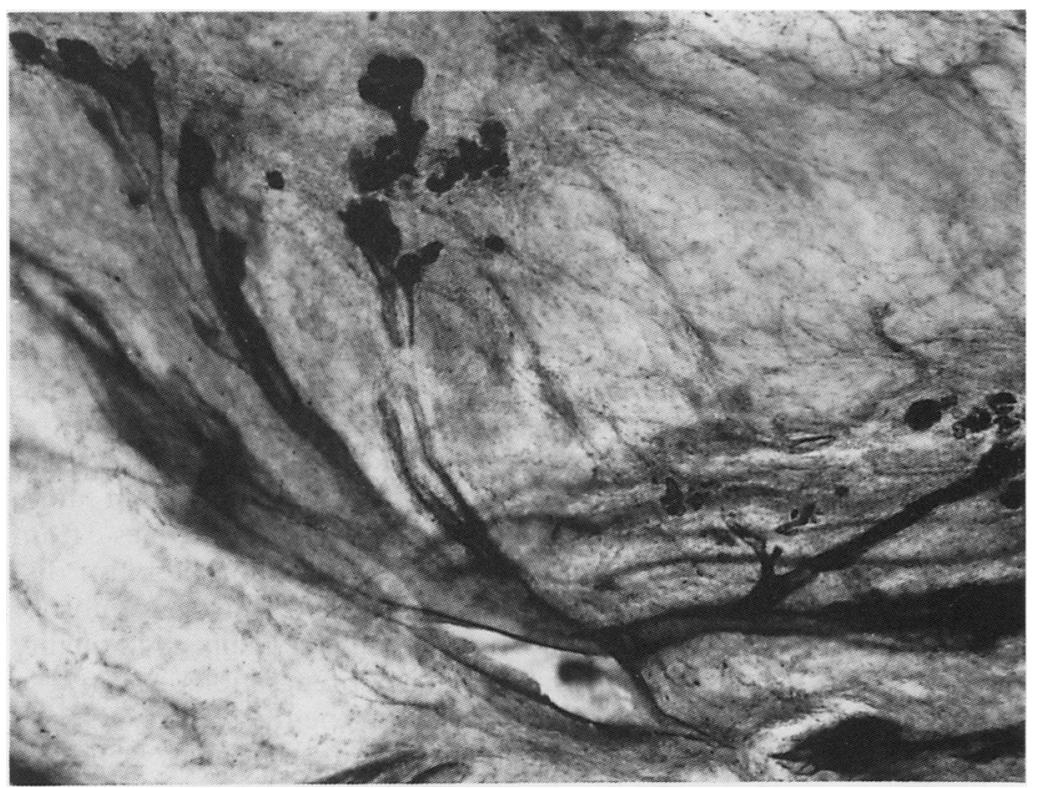

Figure 2 Subgross preparation of backprocessed tissue stained with Mayer's haematoxylin using a subgross technique.

\section{Results}

If incompletely dewaxed tissue is submitted for subgross examination the wax is visible as a translucent unstained area. Wax is retained in particular in the loose perilobular connective tissue. ${ }^{8}$ All depths of tissue were effectively dewaxed using the protocol described. None of the thick sections was damaged by the procedure.

In the reprocessed $5 \mu \mathrm{m}$ sections there was good preservation of both nuclear and morphological detail (fig 1). In fact these sections were indistinguishable from our routine histological sections. Examination of the subgross preparations showed that the results were also comparable with our subgross sections prepared from formalin fixed material (fig 2).

A noticeable problem with the preparation of semithick $(50-100 \mu \mathrm{m})$ and thick $(100-1000 \mu \mathrm{m})$ sections is a propensity to curl up during sectioning. Unrolling such sections has to be performed manually, and the sections subsequently floated out on a $80^{\circ} \mathrm{C}$ water bath. Dewaxed sections uncurled as they dewaxed.

Batch processing in cassettes was as effective as individually processing each specimen by hand, and is a modest saving in labour.

\section{Discussion}

This study shows the effectiveness of using a dewaxing protocol to produce thick sections of breast tissue for subgross examination. The results were indistinguishable from those obtained from conventional formalin fixed tissue. Furthermore, despite our initial doubts, there was no loss of nuclear morphological detail. As this method has been used in the past for producing sections for flow cytometry such a result should be expected.

The demonstration that this technique can be performed in conventional cassettes means that the technique can be fully automated. However, manual processing takes little time, as only infrequent changes of reagents are necessary.

This method is not designed for immediate diagnostic use; it does, however, permit retrospective examination of clinical material. Examination of subgross sections has, in the past, been limited by the restriction of the technique to formalin fixed tissue and the prolonged processing required. This meant that diagnostic tissue could not be examined in this way. Thus the usefulness of the technique was limited by the restricted nature of the material. Secondly, subsequent routine processing was required if the subgross appearance was to be correlated with conventional preparations.

The implications of our method are that after histopathological diagnosis the whole depth and morphology of the lesion can be examined using a subgross technique. Furthermore, small or incidentally found lesions of interest can be specifically selected for examination.

The material can also be reprocessed successfully without loss of nuclear detail. This alleviates worries that tissue submitted for backprocessing and subgross examination cannot be used later for subsequent sectioning at the conventional depth of $5 \mu \mathrm{m}$.

This study has been generously funded by a Wolfson Foundation grant to the Regional Breast Pathology Unit and the tion grant to the Regional Breast Pathology Unit and Committee of the Bristol and Weston Health Authority (JSA).

1 Babiak J, Poppema S. Automated procedure for dewaxing and dehydration of paraffin-embedded tissue sections for flow cytometric analysis of breast tumors. $\mathrm{Am} \mathcal{f}$ Clin Pathol 1991;96:64-9.

2 Ingleby H, Holly C. A method for the preparation of serial slices of the breast. Bulletin of the International Association of Medical Museums 1939;19:93-6.

3 Dabelow A. Die postnatale Entwicklung der menschlichen Milchdruse und ihre Korrelation. Gegenbauer's Morphologisihes fatirbuch 1941;85:361-416.

4 Marcum RG, Wellings SR. Subgross pathology of the human breast: methods and initial observations. $7 \mathrm{NCI}$ 1969;42:115-21.

5 Migliori E. Un metodo di studio submacroscopico dell mammella umana intera. Tumori 1975;61:357-63.

6 Davies JD, Young EW, Mera SL, Barnard K. Lysozyme is a component of vascular elastic fibres. Experientia $1983 ; 39: 382-3$.

7 Manton SL, Ferguson DJP, Anderson TJ. An automated technique for the rapid processing of breast tissue for subgross examination. $\mathcal{f}$ Clin Pathol 1981;34:1 189-91.

8 Nizze H. Zur Biomorphose des Mantelgewebes der wieblichen Brustdruse. Virchows Arch (Pathol Anat) 1972;356:247-58. 